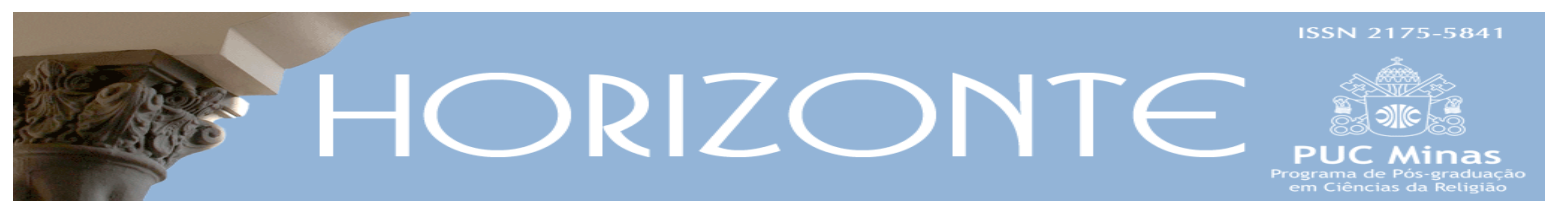

Dossiê: Ordens Religiosas Medievais: Poder e Sociedade - Artigo Original (c) (i)

DOI - 10.5752/P.2175-5841.2017v15n48p1253

\title{
Dominicanos no Reino de Nápoles (séc. XIII e XIV): conflitos e alinhamento político
}

\author{
Domincans at Kingdom of Naples (13th-14th centuries): \\ conflicts and political alignment
}

Igor Salomão Teixeira *

\section{Resumo}

\begin{abstract}
O objetivo deste artigo é apresentar linhas gerais sobre a instalação de conventos da Ordem dos Frades Pregadores (Dominicanos) no reino de Nápoles entre os séculos XIII e XIV. Os documentos utilizados foram: carta de Frederico II aos Dominicanos, atas de capítulos gerais e provinciais, relatos de Bernardo Gui sobre a fundação e divisões de conventos nas províncias da Ordem e documentos pontifícios (bulas). A metodologia consistiu em três etapas: caracterização da diversidade de documentos utilizados; identificação de informações sobre o estabelecimento de conventos na parte meridional da Itália; análise dos dados obtidos na documentação para compor um quadro aproximado das possíveis relações dos frades com a corte angevina e com o papado. A historiografia especializada também foi utilizada de modo a balizar os limites das interpretações a partir dos dados revelados pela documentação. As conclusões apontam para uma articulação complexa entre Frades Pregadores, a casa de Anjou e o papado, tanto na deflagração quanto na resolução de conflitos, principalmente a partir da década de 1260.
\end{abstract}

Palavras-chave: Ordem dos Pregadores; Nápoles; Angevinos;

\begin{abstract}
This paper aims to present a general outline of the institution of the Order of the Preachers' convents in the Kingdom of Naples between the 13th and 14th centuries. Our documentation is composed of: Frederick II's Letter to the dominicans, the acts of the general and provincial Chapters, Bernard Gui's reports on the founding and division of convents in the provinces of the Order and pontifical documents (Papal bulls). Our method consists of three parts: characterizing the variety of documentation used; identify information on the institution of convents in Southern Italy and analyze data drawn from documentation in order to compose an approximate landscape of the possible relations of the friars and the angevin court with the Papacy. The historiography available was employed as a means of delimiting possible interpretations drawn from the data revealed by the chosen documentation. Our conclusion points to a complex articulation of Preachers, the House of Anjou and the Papacy, both in the conflagration as well as in the resolution of conflicts, mainly from 1260 onwards.
\end{abstract}

Key words: Order of Preachers; Naples; Angevins;

Artigo submetido em 03 de setembro de 2017 e aprovado em 26 de dezembro de 2017.

* Doutor em História (UFRGS), professor de História Medieval no Departamento e no Programa de Pós-Graduação em História da UFRGS. Bolsista de Pós-doutorado da CAPES e Pesquisador Associado da École Française de Rome (2017-2018). Para este artigo, agradecemos o apoio da CAPES e da École Française de Rome. País de origem: Brasil. E-mail: teixeira.igor@gmail.com

Horizonte, Belo Horizonte, v. 15, n. 48, p. 1253-1273, out./dez. 2017 - ISSN 2175-5841 


\section{Introdução}

A história do Sul da Itália na Idade Média é cada vez mais marcada pelo debate sobre as especificidades das formações políticas, sociais, econômicas e culturais. Tratar dessas especificidades, no entanto, é um desafio na medida em que predominantemente a historiografia - principalmente a traduzida para o português, ou mesmo a produzida no Brasil - privilegia documentos, processos históricos e acontecimentos ocorridos nas cidades do Norte. Isso levou o historiador Mario del Treppo a afirmar que o Sul da Itália foi durante muito tempo definido como um "Norte mancato", ou seja, que a história da Itália meridional, na Idade Média, é caracterizada pelo distanciamento em relação ao "modelo" identificado na parte centro-setentrional da Península (DEL TREPPO, 1987, p.129-131). Mais recentemente, visando refletir sobre as características próprias daquela região, principalmente entre os séculos XIII e XIV, foi publicada a obra Identités Angevines: Entre Provence et Naples (XIIIe-XVe siècle), (BOYER, MAILLOUX e VERDON, 2016). Esta obra está bastante relacionada à formação de identidades políticas, jurídicas e financeiras. Os autores consideram principalmente a introdução de mãode-obra letrada "francesa" pelos duques de Anjou que assumiram o domínio local após a batalha de Benevento em 1266. Esse debate sobre a questão da identidade angevina no Sul da Itália, entre o reinado de Carlos I e de sua bisneta Joana I, resvala no tema deste artigo na medida em que a inserção e o estabelecimento das Ordens Mendicantes nessa região está diretamente relacionada à questão da presença de estrangeiros e/ou marcadores de identidades, como se pretende analisar.

Os casos mais latentes nos quais "Ordens Mendicantes" e "Identidades angevinas" se encontram são os processos de canonização de Luís de Anjou (inquérito de 1307 e canonização em 1317) e de Tomás de Aquino (inquéritos de 1319 e 1321 e canonização em 1323). Luís e Tomás guardam entre si algumas semelhanças: origem nobre em famílias da região do Sul da Itália; mendicantes (minorita e pregador, respectivamente); canonizados pelo mesmo papa, João XXII. 
Os processos aconteceram no reino de Nápoles e as canonizações foram relativamente rápidas considerando apenas a abertura dos inquéritos, mas entre a morte e a canonização de Luís passaram-se 20 anos enquanto que no caso de Tomás passaram-se 49 anos. Outro fator que aproxima as duas trajetórias é que ambos tiveram contato com os "valores" da vida mendicante e/ou tiveram suas trajetórias como mendicantes fora da região da qual são oriundos. Principalmente Luís de Anjou, que se aproximou da questão em Barcelona, durante o período em que foi refém dos aragoneses após as Vésperas Sicilianas e o tratado de Canfranc, de 1288; além disso, faleceu em 1297 como franciscano e bispo de Toulouse. A trajetória de Tomás de Aquino também é marcada por constantes deslocamentos: desde os estudos com Alberto Magno em Colônia, a atividade docente em Paris até o final da vida, em Nápoles, quando fundou, entre 1272-1273, o que Anne Reltgen-Tallon chamou de "Escola Provincial de Teologia".

Embora esses acontecimentos e essas duas trajetórias sejam do quarto final do século XIII, tanto os Frades Pregadores quanto os Frades Menores instalaram-se na Itália meridional ainda nas primeiras décadas daquele século. Sendo assim, o objetivo deste artigo é traçar linhas gerais que caracterizem a instalação especificamente dos dominicanos no reino de Nápoles. A hipótese que norteia essas reflexões é que a instalação dessas Ordens Religiosas e as relações que seus membros vão estabelecer com os lugares nos quais se instalaram são componentes importantes para se pensar as “identidades angevinas”. Assim, espera-se contribuir com o debate contemporâneo acerca desta temática.

\section{Frades Pregadores: surgimento, organização e primeiros atos institucionais}

Em 2016 comemorou-se, de diversas formas, os 800 anos da fundação da Ordem religiosa por Domingos de Calaruega e o reconhecimento papal, por

\footnotetext{
${ }^{1}$ Segundo a autora, o capítulo provincial de Florença, realizado em 1272, deu uma autonomia inédita a Tomás de Aquino para que ele fundasse, onde escolhesse, um centro de ensino. Esse centro de ensino seria "supra-conventual" em um quadro "estritamente provincial" (RELTGEN-TALLON, 2005, p. 265-271).
} 
Inocêncio III. ${ }^{2}$ Trata-se de uma das histórias mais conhecidas sobre ordens religiosas surgidas na idade média. Neste sentido, apresentamos nesta parte do texto as informações essenciais para o argumento a ser desenvolvido. Cabe explicitar o processo inicial de organização administrativa da Ordem (a realização dos capítulos gerais), as primeiras casas (a criação de Províncias e posteriormente a divisão destas); o recrutamento dos membros e as relações com os poderes temporal e espiritual.

Sobre a presença dos pregadores na Península Itálica, o destaque geralmente recai sobre a região de Bolonha, assim como a província da Lombardia. Para outras regiões, como o Piemonte ou a Campânia, por exemplo, os estudos e informações são mais esparsos. Os dados, amparados pelo que se pode ler nas atas dos capítulos gerais e provinciais, revelam, por exemplo, que nesses dois extremos da Península a presença dos dominicanos foi basicamente simultânea. Grado Merlo afirma que os Pregadores tinham poucas sedes na região subalpina do Piemonte e que a fundação do primeiro convento está situada entre os anos de 1228 e 1234, intensificada na segunda metade daquele século (MERLO, 1985, p. 20-21). Tratou-se, portanto, de uma instalação menor e posterior à dos franciscanos.

Um ano após o texto de Merlo, Luigi Pellegrini publicou um artigo sobre a presença dos mendicantes na região da Campânia. O autor aponta para a chegada dos franciscanos antes dos dominicanos, mas que é possível inferir nos anos de 12171218 como momento das primeiras instalações. Porém, a fundação de conventos, no caso de Trani, é documentada apenas em 1227 através de um testamento no qual é possível encontrar a informação que os frades pregadores estavam construindo uma sede própria. Em relação à presença dominicana em Nápoles, Luigi Pellegrini afirma que é possível assinalar que se tratava de uma preocupação anti-herética. Porém, o silêncio documental das décadas de 1240-1250 é revelador do confronto entre Frederico II e o Papado. De acordo com Pellegrini, o conjunto documental dos

\footnotetext{
2 Pode-se citar aqui desde uma exposição em Buenos Aires à obra L’Ordine dei Predicatori: I Domenicani - storia, figure e istituzioni (1216-2016), (FESTA e RAININI, 2016).
} 
dominicanos em Nápoles é mais fortemente traçado a partir dos anos 1260 (PELLEGRINI, 1986, p.09-41). ${ }^{3}$

Traçar características gerais da instalação, inserção e estabelecimento dos dominicanos em Nápoles também é passar pela história (trágica) da (não) preservação de fundos documentais. Em resumo: pouco restou dos pergaminhos referentes a atos dos séculos XIII e XIV por motivos que vão desde a) um interesse tardio em relação à preservação da memória (e preocupação em relação ao patrimônio) dos conventos (mais intenso entre os séculos XVI e XVII); b) supressão das Ordens Religiosas por Napoleão e c) destruição de fundos documentais no incêndio de 1943 em Villa Montesano em São Paulo Belsito, Nápoles. Sabe-se, por notícias e catálogos, que existia o fundo Pergamene dei monasteri soppressi, com cerca de 32 mil pergaminhos, dispostos em ordem cronológica, em 359 volumes, sem informações sobre a origem dos mesmos e que estavam divididos em duas partes e em um suplemento. A primeira parte continua 648 atos, divididos em 14 volumes, compreendendo o período entre 703-1130. A segunda série, com 28851 atos, tinha 340 volumes e compreendia o período entre 1131-1798. O Supplemento, 401 atos, 5 volumes, período de 1165-1767. Isso implica, segundo Rosalba di Meglio, em entender que os documentos relacionados aos conventos das Ordens Mendicantes estavam contidos na segunda série e no suplemento. Após as trágicas situações, o que sobrou está contido em um fundo chamado Corporazioni Religiose Soppresse ou, no caso do convento S. Domenico Maggiore (dominicanos), salvaguardado pela Società Napoletana di Storia Patria, cujo primeiro inventário em 1962, levantou cerca de 6884 pergaminhos (DI MEGLIO, 2013, p.14-15). ${ }^{4}$

A fundação por Domingos de Gusmão, a autorização e reconhecimento da Ordem dos Irmãos Pregadores, inicialmente por Inocêncio III e confirmada por

\footnotetext{
${ }^{3}$ Voltaremos aos argumentos deste autor, principalmente a partir da obra "Che sono queste novità?" Le religiones novae in Italia meridionale (secoli XIII e XIV), (PELLEGRINI, 2000). Para efeito de comparação com outra região e outro tipo de situação políticogeográfica, cf: Del Fuoco (1996, p. 171-201).

${ }^{4} \mathrm{O}$ estado atual da documentação segue pouco explorado, conforme afirma a autora na medida em que "una più vasta ricostruzione dell'archivio conventuale" está em fase de elaboração. Cf. nota 36, p. 16 (KAEPPELI, 1962, p. 285-326).
} 
Honório III, sob a regra de Santo Agostinho, percorre um período que compreende o final do século XII, a chamada Cruzada Albigense e o IV Concílio de Latrão. A primeira casa fundada, na região de Toulouse, inicia a estruturação dessa Ordem baseada no princípio da mendicância e da pregação itinerante. A partir de 1220 tiveram início as reuniões periódicas, os Capítulos Gerais e, posteriormente, os Capítulos Provinciais. Para compreender os passos atribuídos ao fundador, os atos pontifícios, os procedimentos administrativos internos e os primeiros anos de desenvolvimento da Ordem o pesquisador pode lançar mão de documentos do século XIII que se distinguem tanto pela forma quanto pelo conteúdo. ${ }^{5}$

\section{1) Documentos pontifícios ${ }^{6}$}

a) Atas do IV Concílio de Latrão (1215), concílio ecumênico realizado durante o pontificado de Inocêncio III e que determinou que a fundação de novas ordens religiosas se desse apenas a partir de regras já reconhecidas pelo papado. Essa determinação está relacionada à escolha pela chamada "Regra de Santo Agostinho", que foi adotada pela Ordem dos Pregadores.

b) Religiosam Vitam (1216), de Honório III, que reconhece os privilégios da Ordem. Esta bula apresenta um conjunto de informações que caracterizam a Ordem, inclusive materialmente, no plano hierárquico, jurisdicional e pastoral.

\section{2) Documentos monásticos}

a) Regra de Santo Agostinho, diferentemente da "Regra de São Bento", não se trata necessariamente de um texto pastoral-monástico escrito ou atribuído a Agostinho de Hipona com a finalidade de organização de casas religiosas. O que se conhece como o texto dessa regra é um conjunto de escritos reunidos posteriormente para dar identidade pastoral a algumas casas religiosas. Esse conjunto de textos que

\footnotetext{
${ }^{5}$ Como esses documentos fazem parte de uma "memória institucional" é possível encontrar edições de todo o material. A principal referência para esse tipo de compilação elaborada pela própria ordem é a obra Monumenta Ordinis Fratrum Predicatorum Historica (MOPH), cuja publicação teve início no século XIX.

${ }^{6}$ Esta parte do artigo é bastante devedora da tese de Carolina C. Fortes (2011, p. 22-69).
} 
foi escolhido por Domingos de Gusmão para solicitar a autorização de organização de uma nova ordem religiosa.

\section{3) Documentos institucionais-administrativos ou legislativos}

a) Liber consuetudines, texto-base no qual se transforma a regra da Ordem dos Irmãos Pregadores. Não é um texto estático, na medida em que as decisões dos capítulos gerais, desde que aprovadas em três capítulos consecutivos, podem excluir/inserir/modificar o texto da regra em vigor. Neste sentido, o texto é importante, mas deve ser lido concomitantemente às atas dos capítulos e às Constituições.

b) Atas dos capítulos gerais e provinciais, são os registros das reuniões periódicas nas quais são apresentadas questões conventuais, provinciais e gerais de modo a organizar a vida dos frades no interior dos conventos e da relação desses frades com o saeculum. Nessas atas podem ser encontradas informações diversas, como determinações, imposições de disciplina e punições, autorizações para fundação de novas casas, divisão de províncias, circulação dos frades entre os conventos. O primeiro capítulo geral aconteceu em 1220, um ano antes da morte de Domingos de Gusmão, em Bolonha. Porém, Gregório IX recomendou a realização de uma reunião superior à dos Capítulos Gerais, em 1228.

c) Constituições, são adaptações feitas à Regra. Também foram modificadas algumas vezes ainda no século XIII.

\section{4) Documentos cronísticos e hagiográficos 7}

a) Libellus de Principïs Ordinis Praedicatorum, de Jordão da Saxônia. Escrito entre 1231-1234 pelo segundo mestre geral da Ordem. É um relato sobre Domingos e sobre os primeiros frades a entrarem para a Ordem. Segundo Giulia

\footnotetext{
${ }^{7}$ Para reflexões aprofundadas sobre a importância desses documentos na formação de uma memória institucional da Ordem a referência obrigatória é Luigi Canetti (1996).
} 
Barone não é necessariamente um texto hagiográfico e nem traça uma história de fundação de províncias (BARONE, 2005, p. 431-440). ${ }^{8}$

b) Viate Fratrum, escrita/compilada por Gerardo de Frachet, na década de 1250. Ênfase nas fundações, na pregação contra os hereges. Obra escrita a partir de determinações de um dos capítulos gerais.

c) Legenda Sancti Dominici, de Pedro Ferrando (composta entre 1235-1239); Vita Sancti Dominici, de Constantino de Orvieto (de 1248); Legenda Sancti Dominici, de Humberto de Romans (de 1256). São os primeiros textos hagiográficos sobre o fundador da ordem e que também narram, dentre os seus feitos, os primeiros atos de governo e organização, embora não sejam esses os focos centrais nesses textos.

Esta documentação diversificada e a bibliografia que se dedicou a analisar os primeiros anos da Ordem dão conta de ao menos três aspectos diretamente relacionados com o objeto de estudo em análise: a) uma rápida expansão em número de ingressantes e de casas fundadas (BARONE, 2016, p.05-29) ${ }^{9}$; b) a predileção pela fundação de casas em espaços urbanos com instituições de ensino (Paris, Bolonha, Montpellier, Nápoles) e uma relativa rápida inserção de quadros como docentes nas Universidades (o que motivou inúmeros conflitos); c) desenvolvimento institucional atrelado a alguns procedimentos instituídos tanto pela cúria papal (como a Inquisição a partir da década de 1230) quanto pelo poder temporal (o envolvimento de frades com negócios temporais foi constantemente tratado nos capítulos gerais como algo que só poderia acontecer desde que devidamente autorizado pelos superiores).

\footnotetext{
${ }^{8}$ Carolina Fortes também caracteriza este texto como um texto cronístico e não hagiográfico (FORTES, 2011).

${ }^{9}$ Esta autora aponta o seguinte: “Nel 1277i Predicatori contavano 404 conventi; nel 1303, alla morte di Bonifacio VIII, 554; Fu próprio questo papa che cerco di limitare, o almeno frenare, il moltiplicarsi dele fondazione di nuovi conventi domenicani e francescani ad un'esplicita autorizzazione della Santa Sede. Sembra que le sue misure abbiano raggiunto almeno parcialmente il loro obiettivo: nel 1355 le domus domenicane erano poco più di 600" (BARONE, 2016, p.22).
} 
Esses três itens são importantes na medida em que cada um deles indica diferentes frentes de atuação dos frades. No entanto, antes da chegada dos mendicantes a organização do espaço religioso (em termos de paróquias e de presenças de diferentes expressões de vida religiosa - clérigos, monges, leigos) também é considerada pela historiografia. Rosalba di Meglio, por exemplo, ao tratar do estabelecimento das Ordens Mendicantes em Nápoles, considera o quadro geral das "catholicae maiores" (igrejas com pias batismais e com direitos paroquiais: Santos Apóstolos, São Jorge Maior, São João Maior, Santa Maria Maior) e a capilaridade no interior dessas paróquias com o surgimento de igrejas e capelas menores. Segundo a autora, ao adentrarem nesse território os frades mendicantes tiveram que adotar a "discrição" como estratégia para não entrarem em confronto com a "forte capacità di tenuta delle strutture ecclesiastiche locali" (DI MEGLIO, 2013, p.21-30). ${ }^{10}$ Em estudo anterior, e que corrobora com o argumento de uma entrada discreta dos frades no território, Giovanni Vitolo analisou obituários, testamentos e inscrições de sepulturas em capelas de mosteiros napolitanos. $\mathrm{O}$ autor argumentou que as ordens mendicantes no Sul da Itália não tiveram papel tão exclusivo na vida espiritual dos nobres. Ao constatar poucas doações às Ordens, ou o fato de muitos nobres não estarem enterrados em conventos mendicantes, Vitolo concluiu que os frades, mesmo em 1261, ainda não estavam muito estabelecidos em Nápoles (VITOLO, 2000, p. 553-566).

A partir desses dois estudos é possível, então, identificar um quarto elemento (d): possíveis disputas entre clérigos, leigos, monges e mendicantes sobre o cuidado "das almas" e da relação dos habitantes de Nápoles com o sagrado. Jacques Paul, em estudo sobre a relação entre os frades pregadores, os angevinos e o papado,

\footnotetext{
${ }^{10} \mathrm{~A}$ síntese pode ser localizada na seguinte passagem: "Come si vede, un quadro vivace anche sul piano religioso, quello della Napoli degli inizi del Duecento, con un laicato alla ricerca di un ruolo di protagonista ed una Chiesa cittadina dotata di strumenti efficaci di intervento e che non temeva l'arrivo dei frati, anzi era pronta a utilizzarne le capacità di animazione religiosa. Quanto ai nuovi venuti, nel primo trentennio della loro presenza in città, almeno all'apparenza, non fecero parlare molto di sé e non ebbero quelle occasioni di scontro con il clero parrocchiale, che altrove riempivano le cronache del tempo. La loro presenza fu allora quanto mai discreta: una strategia resa necessaria evidentemente dalla forte capacità di tenuta delle strutture ecclesiastiche locali. Le cose poi in parte cambiarono, ma non tanto per l'appoggio dato ai frati dalla nuova dinastia angioina, quanto piuttosto per la forte accelerazione che nella seconda metà del Duecento ebbe lo sviluppo sociale ed urbanistico della città, con la conseguente difficoltà che ebbero le precedenti istituzioni ecclesiastiche a farvi fronte: difficoltà che consentì ai frati di dispiegare in pieno tutta la loro forza di professionisti della parola e dell'attività pastorale".
} 
sintetizou a situação da seguinte forma: Mendicantes, Poder Espiritual e Poder Temporal. Três "instituições" com regulamentações (legislativas, jurídicas) e costumes nem sempre alinhados. $\mathrm{O}$ autor analisou se o fato de tanto os mendicantes quanto os angevinos estarem de certa forma "atrelados" ou "subordinados" ao papado implicou necessariamente em um alinhamento irrestrito às políticas pontifícias (PAUL, 1998, p. 221-251). A resposta à pergunta, embora seja positiva sim, estavam alinhados - parte de uma questão anterior: a organização da Ordem dos Pregadores, em Províncias, permitia esse alinhamento?

\section{A Província Romana e a Província da Sicília: sobreposição de conflitos, espaço de alianças}

A história das Províncias Dominicanas entre os séculos XIII e XIV pode ser traçada a partir de documentos como as Atas dos capítulos gerais e provinciais. Nesses documentos legislativos e normativos é possível encontrar o que Jacques Paul chama de "notáveis diferenças de uma província a outra". Isso implica, no caso do estudo realizado por este historiador, em propor uma leitura comparada entre atas de capítulos de diferentes províncias e as atas dos capítulos gerais (PAUL, 2001, p. 19-59). ${ }^{11} \mathrm{O}$ caminho seguido neste artigo não é o de pensar especificidades entre diferentes províncias, até mesmo porque, tanto para a província da Provença quanto para a província Romana, internamente elas englobavam especificidades locais expressas em termos políticos, identitários etc conforme se pretende apontar posteriormente sobre a província do Reino da Sicília.

Considerando ainda a província da Provença e as demais, o registro tardio (de 1240) do segundo capítulo geral (1221), informa sobre a divisão da Ordem em Províncias. Porém, quando é feito o registro, a divisão já conta com 8 Províncias: "Hyspaniam, Porvinciam, Franciam, Lombardiam, Romanam...Ungariam, Theotoniam, Angliam” (ACTA CAPITULORUM GENERALIUM, 1898, v.III, p. 02).

\footnotetext{
${ }^{11}$ A leitura cruzada realizada por Jacques Paul englobou temas como a relação dos pregadores com bens em depósito; casamentos e testamentos; além do envolvimento em aspectos políticos (tema que será tratado adiante).
} 
Conforme apontado por M-H Vicaire em 1972, o documento deixado por Bernardo Gui, De Fundatione et Prioribus conventuum provinciarum tolosanae et provinciae ordinis praedicatorum, datado do início do século XIV, é precioso para a compreensão do tamanho da Ordem dos Pregadores naquela região e, praticamente, utilizado por todos os pesquisadores que se debruçam sobre o tema da divisão das províncias entre os dominicanos (VICAIRE, 1973, p. 1017-1041). Porém, esse tipo de documento não existe para outras províncias da Ordem.

O registro dos Capítulos Gerais informa também sobre alguns conflitos e alinhamentos. Segundo Gerardo Cioffari, Frederico II, por exemplo, adotou uma postura contra os frades que atacavam sua política, enviando ao Capítulo de 1241 o seguinte documento:

Ceterum quia totius mundi conscientia in vestre religionis honestae firmatur et vagos discursus hominum evangelizando salutis et gratie documenta dirigitis, novam mundo conscientiam de vobis fieri non velitis quod aliqui fratrum vestrorum cum literis et legationibus contra nos et imperium per orbem discurrere sugillentur, dicentes quod se Deo in salutem animarum suarum obsequium prestare confidant si nobis et imperiuo nostro se molestos et injuriosos opponant. (CIOFFARI, 1993. Vol.1. p. 23). ${ }^{12}$

Ameaça cumprida com a expulsão dos frades, após estes terem apoiado as excomunhões impostas por Gregório IX e Inocêncio IV. A expulsão foi documentada no Capítulo Geral de 1250, no qual foi registrado que todos os priores da Província Romana, do reino de Frederico, deveriam ter respeitadas as prerrogativas de suas funções nas reuniões futuras (ACTA CAPITULORUM GENERALIUM, 1898, v.III, p. 54). ${ }^{13}$

As controversas relações entre o imperador Frederico II e os Pregadores estão narradas também em outros documentos, como na obra de Gerardo de Frachet

\footnotetext{
${ }^{12}$ Carta de Frederico Il ao Capítulo Geral dos Dominicanos, Paris, 27 de fevereiro de 1241.. O documento, segundo Cioffari, está editado em HUILLARD-BRÉHOLLES (1859, t.V, p.1100).

13 "Omnes priores Romane provincie, de regno domini Frederici expulsos absolvimus, et mandamus quod fratres inde expulsi in proximo provinciali capitulo certis conventibus assignentur".
} 
(Vitae Fratrum) ou na Cronaca di Riccardo da S. Germano (notário do imperador). Segundo Giulia Barone, que considerou, além da Cronaca di Riccardo da S. Germano, a documentação diplomática do imperador, o contexto da expulsão dos mendicantes das terras do imperador é o de "fechamento das fronteiras" na medida em que, naquele momento, havia um confronto entre o imperador e as comunas na Lombardia (BARONE, 1978, p. 607-626).

As atas dos capítulos da Província Romana, entre 1243-1344, revelam alguns aspectos importantes. O primeiro deles é a extensão territorial. Esta questão é importante na medida em que uma Província não necessariamente cobria uma região homogênea em termos políticos. A Província da Provença, por exemplo, cobria a França meridional que, na Idade Média, abarcava regiões sob domínio político de capetíngios, ingleses e aragoneses. A Província Romana cobria toda a Península Itálica, com exceção da região da Lombardia (que era uma Província específica). Isso implica em considerar que as alianças dos frades com os poderes locais não necessariamente agradariam ou estariam alinhadas com os interesses papais. Exemplo disso: a negativa de João XXII em relação à abertura do processo de canonização do dominicano Raimundo de Peñafort porque a demanda foi apresentada pela coroa aragonesa. Em contrapartida, o mesmo papa canonizou Luís de Anjou (irmão do rei de Nápoles à época) e Tomás de Aquino (de origem nobre da mesma região e que, para Jean-Paul Boyer, era um “santo do reino”). (BOYER, 2005, p. 277-312).

As atas do período entre 1260 e 1268, por exemplo, podem ser lidas a partir da perspectiva do alinhamento, conforme apontado por Jean Paul Boyer, citado anteriormente. No capítulo realizado em Viterbo (1264), foi anotado o seguinte: "volumus et monemus quod fratres non relaxent linguas suas contra prelatos ecclesie et maxime Romane curie” (ACTA CAPITULORUM GENERALIUM, 1941, v.XX), ou seja, que os frades contivessem suas línguas e não falassem contra prelados da ecclesia e da cúria Romana. Caso contrário, os superiores desses frades deveriam 
puni-los. Em 1266, em Todi, o alinhamento se deu a partir de um elogio ao Rei Carlos: aos frades são ordenados a se referirem sempre ao rei (que semper speciali dilectione ordinem nostrum dilexit et protector, ou seja, que sempre teve uma predileção e protegeu a ordem) de forma honrosa. Da mesma forma como no registro de 1265, caso contrário, deviam ser punidos pelos superiores (ACTA CAPITULORUM GENERALIUM, 1941, v.XX). ${ }^{14}$ Em 1267 (Luca) e 1268 (Viterbo) tanto a figura do papa quanto a do rei reaparecem em uma recomendação: que os frades falem bem (ACTA CAPITULORUM GENERALIUM, 1941, v.XX). ${ }^{15}$

Outro aspecto que envolve a organização das províncias, conforme aponta Luigi Pellegrini em seus estudos, é a forma inexata como alguns territórios aparecem mencionados na documentação. O autor chama atenção específica para a "Terra di Lavoro" - região da atual Campânia, cuja capital é Nápoles. Pellegrini argumenta que essa parte do território era bem definida pelos Frades Menores, enquanto que para os Frades Pregadores havia certa indeterminação (PELLEGRINI, 1986, p.5559).

A partir da lista de conventos elaborada por Bernardo Gui no início do século XIV é possível perceber que o território atual italiano era dividido, para os dominicanos, em quatro províncias: Provincia Romana; Provincia regni Siciliae, Provincia Lombardia inferioris e Provincia Lombardia superioris. Em relação à província da Sicília, o dominicano escreveu:

In provincia regni Siciliae

Monasterium S. Annae Interamnis conventos de Salerno in terra Laboris, quod quase in nemore positum est.

Monasterium S. Petri apostoli ad castellum in civitate Neapoli, in monasterio ubi erant prius monachi nigri, quibus inde depulsis, fundatum extitit \& dotatum a domino Carolo rege Siciliae consenso \& auctoritate Bonifacii papae VIII. ad instantiam ipsus regis, \& magis principaliter supplicantis, anno Domini MCCC. ubi rex \& regina posuerunt sororem

\footnotetext{
14 “Quoniam illustris rex Karolus semper speciali dilectione ordinem nostrum dilexit et protector eius ubique fuit, monemus et mandamus fratribus universis quod ubique et semper eius honori tam verbis quam factis intendant; et si qui inventi fuerint contrarium facere, per priores et visitatores durius puniantur et nihilominus priori provinciali per litteras studeant nuntiare."

${ }^{15}$ (1267) "Admonemus quod fratres bene loquantur de domino papa et rege Carulo."; (1268) "Volumus quod fratres de domino papa et dominis cardinalibus bene loquantur et honeste, et excessus ecclesie quantum possunt commendent et excusent. Idem etiam de domino rege Sycilie volumus observari."
} 
Elizabeth germanam ipsus reginae, filiamque regis Hungariae, quae alias fuerat soror in monasterio de Insula sororum ordinis in Hungaria. Monasterium S. Luciae de Barulo in Apulia in dioecesi Tranensi. Monasterium sanctae Mariae Magdalenae de Muscuso in terminis conventos Aquilani.

Monasterium S. Mariae Annunciatae in ipsa civitate Aquilae.

Monasterium S. Catharina in Sulmona.

Monasterium S. Catharinae in Panormo.

Monasterium S. Eucaristiae in Aquila. (BERNARDO GUI, 1729, col.539548).

A partir desta listagem é possível perceber alguns dados interessantes. O convento sobre o qual o autor dominicano inseriu o maior número de informações é o convento de São Pedro Apóstolo, em Nápoles, a dotação pelo Rei e a autoridade consentida pelo papa Bonifácio VIII. No entanto, um lugar geograficamente bastante próximo de Nápoles, Benevento - também uma das principais cidades da Campânia atual - está na lista dos conventos da Provincia Romana. Além do Monasterium S. Dominici, em Benevento, outras localidades distantes umas das outras aparecem na mesma província, como Florença (Monasterium de Ripolis e Monasterium $S$. Dominici); Roma (Monasterium S. Sixti...fundatum a B. Dominico); Luca (Monasterium S. Mariae de Angelis); Spoleto (Monasterium de Fulgineo in ducatu Spoletano). (BERNARDO GUI, 1729, col.543).

\section{O texto Numerus Monasteriorum Monialium Ordinis Fratrum} Praedicatorum, de Bernardo Gui, portanto, oferece alguns elementos para a compreensão sobre o "tamanho" da Ordem dos Pregadores no início do século XIV, porém, é insuficiente no que tange ao fornecimento de informações sobre as instalações dos frades na parte meridional da Península. As quatro listas que Bernardo Gui apresenta sobre a fundação de casas dominicanas seguem um padrão: quando o autor julgou importante, a casa e sua localização são acompanhadas de informações, como a que apresentou sobre Nápoles e que também podem ser encontradas sobre S. Sixto em Roma, ou S. Catharinae, em Alba, fundado pelo bispo Bonifácio e no qual foram introduzidas irmãs em 1305. Observação como essa também é encontrada para outras regiões, como na Hungria, cuja casa foi fundada pelo rei, Bela, e onde viveu Margarida, virgo electa (BERNARDO GUI, 1729, col.544-545). 
Para Luigi Pellegrini, a imprecisão em relação à "Terra di Lavoro" está relacionada ao fato desta região não ter tido uma "configuração autônoma":

inserita fino al 1294 nella vastissima provincia di Tuscia (o Romana), che si estendeva dalla Toscana alla Sicilia, fece poi parte della grande "provincia del Regno di Sicilia" fino al 1378, quando da tale circoscrizione venne staccata l'isola, che fu costituita in provincia autonoma. Anche quando nel 1445 la circoscrizione continentale del meridione d'Italia venne smembrata com la costituzione della vicaria independente di Calabria, divenuta provincia nel 1530, la provincia di Terra di Lavoro rimase estesa a comprendere la maggior parte dei territori meridionali dall'Adriatico al Tirreno campano. (PELLEGRINI, 1986, p. 107).

A partir desta citação, na qual o autor considera a data de 1294-1295 como o momento da criação de uma circunscrição mais precisa - a Província do Reino da Sicília - é possível, então, propor algumas sínteses sobre o estabelecimento dos frades Pregadores em Nápoles.

Para Gerardo Cioffari, é possível caracterizar, próximo a 1294, os conventos ou casas. Mesmo que não se trate de data de fundação, o registro documental sobrevivente aponta maior concentração de documentos entre 1283-1294. Além disso, o autor ainda aponta dois conventos ou casas sem datação (Fondi e Trapani), somando um total de 34 sedes dominicanas abaixo listadas (as datas referem-se à dos documentos mais antigos):

S. D. de Nápoles, 1231

Trani, 1233

Brindisi e Barletta, 1238

Messina e Cosenza, 1240

Capua, 1253

Gaeta, 1255

Benevento, 1259

Siracusa, 1260

Foggia, 1269

Salerno, 1272

Sulmona, Monopoli, e Catani, 1273

Aquila, 1276 
Bari, Augusta, Piazza, Palermo, Chieti e Penne, 1283

Atri, 1284

Atessa, 1287

Aversa e Taranto, 1288

Sessa, 1291

Manfredonia, 1293

S. P. M. Nápoles, Somma, Venosa e Ortona, 1294. (CIOFARI, 1993, p. 23).

A criação da Província do Reino da Sicília foi inicialmente confirmada com a bula Clara Ordinis Fratrum Praedicatorum Religio, 01 de setembro de 1294, de Celestino V. ${ }^{16}$ Como se sabe, o curto pontificado de Celestino V (julho a dezembro de 1294) foi acompanhado da ascensão ao trono pontifício por Bonifácio VIII, que anulou os atos de seu predecessor. A Província do Reino da Sicília necessitou de nova confirmação, obtida na bula Attendentes ab olim, de 01 de março de 1295. O que o estudo de Pellegrini não aborda, mas foi considerado por Cioffari, é a crise institucional interna vivida pelos frades Pregadores na década de 1290, levada a cabo com a deposição, pelo papa Nicolau IV, do mestre geral Múnio de Zamora. (VARGAS, 2011). ${ }^{17}$

\section{Considerações finais}

A chegada dos frades Pregadores e a instalação de casas pode ser documentalmente traçada a partir de 1227. Entre 1230-1260 as controvérsias entre papado e império afetaram diretamente a permanência dos mendicantes na região. É possível perceber isso pelo tom de "ameaça” do imperador na carta que enviou ao Capítulo Geral de 1241, realizado em Paris. A ameaça pode ter sido concretizada na medida em que o registro do Capítulo Geral de 1250. A retomada dos espaços pelos frades Pregadores só aconteceria, segundo Gerardo Cioffari, com os angevinos e, principalmente, após o contexto das Vésperas Sicilianas, com Carlos II, de Anjou. Porém, para o período anterior às Vésperas, conforme relatado nas atas dos capítulos

\footnotetext{
${ }^{16}$ O documento está compilado no Bullarium Ordinis Praedicatorum (1739, VIII, p. 49-50) e foi traduzido por CIOFFARI (1993, p.39-40).

${ }^{17}$ Agradeço a Luiz Otávio Carneiro Fleck a indicação da obra e suas reflexões em sua pesquisa em andamento.
} 
provinciais de 1264, 1266, 1267 e 1268 (o que coincide com a vitória angevina na Batalha de Benevento e a derrota do sucessor de Frederico II, Manfredo).

Sistematizando as informações e análises apresentadas neste artigo é importante considerar que a inserção dos frades mendicantes em geral e, principalmente, dos Irmãos Pregadores, no Sul da Itália, foi um processo complexo que envolveu reconhecimento, não reconhecimento, ocupação de espaços, expulsões e alinhamento religioso e político com o papado no confronto contra Frederico II. Porém, no mesmo momento em que a parte meridional da Província Romana recebia a autorização para ser dividida, na década de 1290, tanto o papado quanto a Ordem e o poder político dos Anjou passavam por crises internas ou externas: Sucessão de Celestino V para Bonifácio VIII e anulação os atos do predecessor; deposição do Mestre Geral dos Pregadores, Múnio de Zamora; retomada política no reino após as Vésperas Sicilianas.

A partir do que foi apresentado aqui pretendeu-se analisar como a inserção de um grupo específico - uma Ordem religiosa mendicante, a dos Pregadores, fundada na França Meridional em 1216 - em diferentes regiões da Europa Ocidental pode ser reveladora de estratégias não padronizadas de envolvimento em conflitos e/ou nas tentativas de resolução dos mesmos. No caso dos Pregadores no reino de Nápoles, a história perpassada engloba uma imprecisão inicial na denominação das casas presentes na região, a inserção dessas casas em uma Província territorialmente extensa e sua posterior divisão (Província Romana e Província do Reino da Sicília), o que só acontece no final do século XIII. Além disso, em termos documentais, a trágica história da (não) preservação de fundos documentais numerosos produz uma coincidência (que pode ser apenas pelo efeito da destruição dos acervos em calamidades como terremotos e incêndios): a intensificação da atividade dos frades pregadores a partir da década de 1260, coincidindo com a tomada do poder pelos angevinos após a Batalha de Benevento e com os registros elogiosos nas atas dos capítulos provinciais. 


\section{DOCUMENTAÇÃO}

ACTA CAPITULORUM GENERALIUM: 1220-1303. Ed. Fr. Benedictus Maria Reichert. Monumenta Ordinis Fratrum Praedicatorum Historica, Roma, 1898. Vol. III.

ACTA CAPITULORUM PROVINCIALIUM PROVINCIAE ROMANAE : 1243-1344. Ed. Thomas Kaeppeli, Monumenta Ordinis Fratrum Praedicatorum Historica, Roma, 1941. Vol.XX.

BERNARDO GUI. De Fundatione et Prioribus conventuum provinciarum tolosanae et provinciae ordinis praedicatorum. Editado por P. A. Amargier, OP. (MOPH, XXIV), Roma, 1961.

BERNARDO GUI. Historia fundationum conventuum ordinis praedicatorum Tolosanae et Provinciae Provinciarum. Apud: MARTĖNE, Edmundi e DURAND, Ursini. (Orgs). Veterum Scriptorum et Monumentorum historicorum, dogmaticorum, moralium, amplíssima collectio. Tomo VI. Paris: Montalant, 1729. pp. 437-539.

BERNARDO GUI. Numerus Monasteriorum Monialium Ordinis Fratrum Praedicatorum. Apud: MARTÈNE, Edmundi e DURAND, Ursini. (Orgs). Veterum Scriptorum et Monumentorum historicorum, dogmaticorum, moralium, amplíssima collectio. Tomo VI. Paris: Montalant, 1729. pp.539-548.

BULLARIUM ORDINIS PRAEDICATORUM, VII, Roma, 1739.

ESTEVÃO DE SALANIACO E BERNARDO GUI. De quatuor in quibus Deus Praedicatorum ordiniem insignivit. Editado por Th. Kaeppeli, OP. Monumenta Ordinis Fratrum Praedicatorum Historica, Roma, 1949. Vol. XXII

HONÓRIO III. Religiosam Vitam (22 de dezembro de 2016). APUD: SS. Honorius III Bullarium (Cherubini, vol 1, o9o-098). Disponível em: http://www.documentacatholicaomnia.eu/o1p/12161227,_SS_Honorius_III,_Bullarium_(Cherubini_vol_1_090-098),_LT.pdf. Consultado em agosto de 2017.

JORDAO DA SAXÔNIA. Libellus de principiis Ordinis Praedicatorum. Editado por H. Scheeben. Monumenta historic sancti patris nostri Dominici, II. Monumenta Ordinis Fratrum Praedicatorum Historica, Roma, 1935. Vol. XVI. 


\section{REFERÊNCIAS}

BARONE, G. Il Libellus de initio Ordinis fratrum Preadicatorum e lo sviluppo dell'Ordine nel primo cinquantennio. In: Domenico di Caleruega e la nascita dell'Ordine dei Frati Predicatori. (Atti del XLI Convegno storico Internazionale, Todi, 10-12 outubro 2004) Spoleto: Centro Italiano di studi sul basso medioevo - Accademia Tubertina, 2005.pp. 431-440.

BARONE, G. Federico II di Svezia e gli Ordini Mendicanti. In: Mélanges de l'Ecole française de Rome. Moyen-Age, Temps modernes, tome 90, $\mathrm{n}^{\circ}{ }^{2}$. 1978. pp. 607-626

BARTOLI LANGELI, A; BUSTERO, G. P. I documenti di contenuto economico negli archivi conventual dei Minori e dei Predicatori nel XIII e XIV secolo. In: L'economia de Conventi dei Frati Minori e Predicatori fino lla metà del trecento (Atti del XXXI Convegno Internazionale della Società Internazionale di studi francescani e del Centro interuniversitário di studi francescani, ottobre 2003). Spoleto: Fundazione centro italiano di studi sull'alto medioevo, 2004. pp. 119-150.

BARONE, G. "L'età medievale (XIII-XIV secolo). In: FESTA, G. e RAININI, M. (Orgs) L'Ordine dei Predicatori; I Domenicani - storia, figure e istituzioni (12162016). Bari-Roma: Gius. Laterza \& Figli, 2016. p. 05-29.

BOYER, J-P.; MAILLOUX, A. e VERDON, L. (Orgs). Identités Angevines: Entre Provence et Naples (XIIIe - XVe siècle). Aix-en-Provence: PUP, 2016.

BOYER, J-P. Sapientis est ordinare. La monarchie de Sicile-Naples et Thomas d'Aquin (de Charles Ier à Robert). In: DE CEVINS, M-M. e MATZ, J-M. (Orgs). Formation Intellectuelle et culture du Clergé dans les territoires angevins (Milieu du XIIIe-Fin du XVe siècle). Roma: École Française de Rome, 2005. pp. 277-312.

BOYER, J-P. La noblesse dans les sermons des dominicains de Naples (première moitié du XIVe siècle). In: COULET, N. e MATZ, J-M.l (Orgs). La Noblesse dans les territoires angevins à la fin du Moyen Âge. Roma: École Française de Rome, 2000. pp. 567-583.

BOYER, J-P. Prédication et État napolitain dans la première moitié du XIVe siècle. In: L'état Angevin: Pouvoir, Culture Et Société Entre Xiiie Et Xive Siècle. Roma: École Française de Rome, 1998. pp. 127-157.

CANETTI, L. L'invenzione della memoria: il culto e limmagine di Domenico nella storia dei primi Frati predicatori. Spoleto: Centro Italiano di Studi sull'alto medioevo, 1996.

CANETTI, L. Intorno all”idolo dele origini. La storia dei primi frati Predicatori”. Quaderni di Storia Religiosa, III, Verona, 1996. pp. 09-15.

CIOFFARI, G. Il Medioevo. In: IDEM e MIELE, M. Stori dei Domenicani nell'Italia meridionale. Napoli-Bari: Editrice Domenicana Italiana, 1993. Vol.1. 
DEL FUOCO, M G. Insediamento e sviluppo dell'ordine dei frati Predicatori in Germania nel secolo XIII. Quaderni di Storia Religiosa, III, Verona, 1996. pp. 171-201.

DI MEGLIO, R. Ordini Mendicanti: Monarchia e dinamiche politico-sociali nella Napoli dei Secoli XIII-XV. Raleigh: Aonia edizioni, 2013.

DI MEGLIO, R. Ordres mendiants et économie urbaine à Naples entre Moyen Âge et époque moderne. L'exemple de Sant'Agostino. In: BÉRIOU, N. e CHIFFOLEAU, J. (Orgs). Économie et religion: L'expérience des ordres mendiants (XIIIe-XVe siècle). Lyon: PUL, 2009. pp. 591-636.

DUNBABIN, J. Charles I of Anjou: Power, Kingship and State-Making in Thirteenth-Century Europe. Londres; Nova Iorque: Longman, 1998.

FESTA, G. e RAININI, M. (Orgs) L'Ordine dei Predicatori; I Domenicani - storia, figure e istituzioni (1216-2016). Bari-Roma: Gius. Laterza \& Figli, 2016.

FORTES, C. C. Societas Studii: a construção da identidade e os estudos naOrdem dos Frades Pregadores do século XIII. 2011, 370f. Tese (Doutorado em História). Niterói UFF. Disponível em: http://www.historia.uff.br/stricto/td/1344.pdf. Consultado em agosto de 2017.

HUILLARD-BRÉHOLLES, J.L. Historia diplomatica Friderici secundi, sivi Constitutiones, privilegia, mandata instrumenta que supersunt istius imperatories et filliorum eius. Paris, $1859, \mathrm{t} . \mathrm{V}$,

KAEPPELI, T., OP. Dalle Pergamene di S. Donenico di Napoli: Rilievo dei domenicani ivi menzionati con due appendici sui priori conventuali e provinciali fino al 1500. AFP, vol.XXXXII. Roma: Istituto Storico Domenicano S. Sabina, 1962 , p. 285-326.

MERLO, G. G. Minori e Predicatori nel Piemonte del Duecento: gli inizi di una presenza. In: Piemonte Medievale: Forme Del Potere E Della Società: Studi per Giovanni Tabacco. Torino: Einaudi, 1985. pp. 208-226.

PACIOCCO, R. Angioini e 'Spirituali'. Idiffrenti piani cronologici e tematici di un problema. In: L'état Angevin: Pouvoir, Culture Et Société Entre Xiiie Et Xive Siècle. Roma: École Française de Rome, 1998. pp. 253-287.

PANARELLI, F. La cultura dei monaci del Regno di Napoli. In: DE CEVINS, M-M. e MATZ, J-M (Orgs). Formation Intellectuelle et culture du Clergé dans les territoires angevins (Milieu du XIIIe-Fin du XVe siècle). Roma: École Française de Rome, 2005. pp. 09-21.

PAUL, J. “Angevins, frères prêcherus et papauté”. In: L'état Angevin: Pouvoir, Culture Et Société Entre Xiiie Et Xive Siècle. Roma: École Française de Rome, 1998. pp. 221-251. 
PAUL, J. "Les frères Prêcheurs de la province de Provence". Cahiers de Fanjeaux, n.36: L'ordre des Prêcherus et son histoire en France méridionale. Fanjeaux: Privat, 2001. pp. 19-59.

PELLEGRINI, L. “Che sono queste novità?” Le religiones novae in Italia meridionale (secoli XIII e XIV). Napoles: Liguori, 2000.

PELLEGRINI, L. Territorio e città nell'organizzazione insediativa degli ordini mendicante in Campania. Rassegna Storica salernitana, III/1, 1986. pp. 09-41.

PELLEGRINI, L. Gli insediamenti degli ordini mendicante a la loro tipologia. Considerazioni metodologiche e piste di ricerca. Mélanges de l'École Française de Rome: Moyen-Age, Temps modernes, tomo 89, n.2, 1977, pp. 563-573.

RELTGEN-TALLON, A. L'Italie angevine, laboratoire des études dominicaines? L'enseignement de Thomas d'Aquin à Naples (1272-1273). In: DE CEVINS, M-M. e MATZ, J-M. (Orgs). Formation Intellectuelle et culture du Clergé dans les territoires angevins (Milieu du XIIIe-Fin du XVe siècle). Roma: École Française de Rome, 2005. pp. 265-275.

RELTGEN-TALLON, A. Le procès en canonisation de saint Dominique et sa postérité dans la littérature dominicaine. In: Domenico Di Caleruega E La Nascita Dell'ordine Dei Frati Predicatori. (Atti del XLI Convegno storico Internazionale, Todi, 10-12 outubro 2004) Spoleto: Centro Italiano di studi sul basso medioevo - Accademia Tubertina, 2005.pp. 491-510.

VARGAS, M. A. Taming a Brood of Vipers: Conflict and Change in FourteenthCentury Dominican Convents. Leiden; Boston: BRILL, 2011.

VICAIRE, M.-H. Le développement de la province dominicaine de Provence (1215-1295). Annales. Économies, Sociétés, Civilisations. 28e année, N. 4, 1973. pp. 1017-1041; Disponível em: http://www.persee.fr/doc/ahess_0395-2649_1973_num_28_4_293400. Consultado em agosto de 2017. doi: 10.3406/ahess.1973.293400.

VITOLO, G. La noblesse, les ordres mendiants et les mouvements de reforme dans le royaume de Sicile. In: COULET, N e MATZ, J-Ml (Orgs). La Noblesse dans les territoires angevins à la fin du Moyen Âge. Roma: École Française de Rome, 2000. pp. 553-566.

VITOLO, G. Il monachesimo benedettino nel Mezzogiorno angioino: tra crisi e nuove esperienze religiose. In: L'état Angevin: Pouvoir, Culture Et Société Entre Xiiie Et Xive Siècle. Roma: École Française de Rome, 1998. pp. 205-220. 